\title{
Structural Analysis of Underivatized Neutral Human Milk Oligosaccharides in the Negative Ion Mode by Nano-Electrospray MS $^{\mathbf{n}}$ (Part 1: Methodology)
}

\author{
Anja Pfenninger* and Michael Karas \\ Institute of Pharmaceutical Chemistry, J. W. Goethe University, Frankfurt/Main, Germany \\ Berndt Finke and Bernd Stahl \\ Numico Research Group Germany, Friedrichsdorf/Taunus, Germany
}

\begin{abstract}
Underivatized neutral oligosaccharides from human milk were analyzed by nano-electrospray ionization (ESI) using a quadrupole ion trap mass spectrometer (QIT-MS) in the negative-ion mode. Under these conditions neutral oligosaccharides are observed as deprotonated molecules $[\mathrm{M}-\mathrm{H}]^{-}$with high intensity. CID-experiments of these species with the charge localized at the reducing end lead to C-type fragment ions forming a "new" reducing end. Fragmentations are accompanied by cross-ring cleavages that yield information about linkages of internal monosaccharides. Several isomeric compounds with distinct structural features, such as different glycosidic linkages, fucosylation and branching sites were investigated. The rules governing the fragmentation behavior of this class of oligosaccharides were elucidated and tested for a representative number of certain isomeric glycoforms using the MS/MS and $\mathrm{MS}^{\mathrm{n}}$ capabilities of the QIT. On the basis of the specific fragmentation behavior of deprotonated molecules, the position of fucoses and the linkage type (Gal $\beta 1 \rightarrow 3$ GlcNAc or Gal $\beta 1 \rightarrow 4$ GlcNAc) could be determined and linear and branched could be differentiated. Rules could be established which can be applied in further investigations of these types of oligosaccharides even from heterogenous mixtures. (J Am Soc Mass Spectrom 2002, 13, 1331-1340) (c) 2002 American Society for Mass Spectrometry
\end{abstract}

$\mathrm{T}$ The increased understanding of the ubiquitous role of carbohydrates in biology forms the basis for a new scientific discipline, glycobiology [1]. It creates new demands for analytical tools for structure elucidation of complex oligosaccharides comprising composition, sequence, branching, and linkage analysis, including anomericity and finally also ring sizes and absolute configuration, i.e., identity of the subunits. Mass spectrometry (MS) offers the possibility of structural investigations of oligosaccharides; this has been demonstrated using fast atom bombardment (FAB-MS) $[2,3]$. Electrospray (ESI) MS and matrix-assisted laser desorption ionization (MALDI) MS have been applied to the investigation of carbohydrates of biological origin $[4,5]$. Their ability to deliver structural information on different levels depends on the mass analyzer coupled to the ion source. In general, mass spectrometry pro-

Published online September 30, 2002

Address reprint requests to Dr. M. Karas, Institute for Pharmaceutical Chemistry, Biocenter, J. W. Goethe University Frankfurt, Marie-Curie Str. 9-11, D-60439 Frankfurt, Germany. E-mail: karas@iachem.de

*Current address: Aventis Pharma Deutschland $\mathrm{GmbH}$, Industriepark Höchst, 65926 Frankfurt/Main, Germany. vides the possibility of structural elucidation based on characteristic fragmentations of the molecules under investigation. A nomenclature for the possible fragment ions of oligosaccharides has been proposed by Domon and Costello [6], i.e., $\mathrm{B}$ and $\mathrm{C}$ for fragment ions containing the nonreducing side, $\mathrm{Y}$ and $\mathrm{Z}$ for those containing the reducing sugar unit, as well as $A$ and $X$ type fragment ions for those arising from cross-ring cleavages.

In MALDI-MS neutral oligosaccharides are usually observed as singly-cationized (typically sodiated) species [7], which offers a simple means for screening complex mixtures. As MALDI is mostly coupled to a time-of-flight (TOF) mass analyzer, options for structural analysis are restricted to metastable fragment-ion analysis post-source decay (PSD) [8]. Some successful attempts for structure elucidation have been made for underivatized and derivatized oligosaccharides by MALDI/PSD analysis [9-15]. However, fragmentation is poorly controllable, but some progress has been reported by the choice of the matrix [16], the analysis of in-source-decay fragments using delayed extraction (DE) [17] or the use of a collision cell prior to mass 
analysis in a time-of-flight mass spectrometer (MALDICID/PSD-TOF-MS) [18]. Also, the combination of MALDI/MS and enzymatic degradation [19-23] or chemical (alkaline) degradation [24] has been successfully applied to underivatized oligosaccharides. In the latter case a FT-ICR (Fourier Transform-Ion Cyclotron Resonance) mass analyzer was used for MS/MS of the degraded fragments. Also collision-induced dissociation (CID) experiments of in situ derivatives of hydrogen sulfateattached molecular ions [25] have been applied to gain structural information using this type of mass analyzer.

The most widely used mass spectrometric approach for structural elucidation of oligosaccharides is ESItandem-MS, typically performed on triple-quadrupole instruments using precursor-ion selection in a first MS step, collision-induced dissociation and mass analysis of fragment ions in a second MS step [4, 26, 27]. This is mainly carried out with sodiated derivatized (permethylated or peracetylated) oligosaccharides [28-31] for two major reasons: (1) To reach the sensitivity level required and then to enhance the yield of significant fragment ions, (2) sequence, branching, and linkage analysis can be performed based on the identification of nonreducing terminal fragment ions due to cleavage of glycosidic bonds and linkage-specific additive mass increments due to cross-ring cleavages. Both derivatized and underivatized saccharides have also been investigated in $\mathrm{MS}^{\mathrm{n}}$ experiments using doubly-charged metal-cation attached precursor ions, i.e., $[\mathrm{M}+\mathrm{Cat}]^{2+}$ (Cat : $\mathrm{Mg}^{2+}, \mathrm{Ca}^{2+}[32], \mathrm{Ni}^{2+}[33]$, or $\left.\mathrm{Co}^{2+}[34,35]\right) . \mathrm{MS}^{\mathrm{n}}$ investigations of protonated, permethylated oligosaccharides in a quadrupole ion-trap mass spectrometer were reported to give simpler and more predictable mass spectra based on the predominant formation of B-type fragment ions [36].

For nonderivatized oligosaccharides, linkage-specific cross-ring fragments are observed, too; this has been shown for small oligosaccharides accessible by fast atom bombardment (FAB), laserdesorption/ionization (LDI) or electrospray/ionization (ESI); cross-ring fragment ions are found both in the positive [37-41] and negative ion mode $[42,43]$ and are believed to originate from a ring opening at the reducing end sugar in a pericyclic hydrogen rearrangement of the retro-aldol reaction type [37] (see Scheme 1). This may be followed by cleavages after enolization, resulting in loss of linkage-specific neutral fragments. However, it could be proven by ${ }^{18} \mathrm{O}$ exchange of the reducing end oxygen that for underivatized oligosaccharides in the positive ion mode predominantly glycosidic bond cleavages of B/Y-type occur and only the linkage of the reducing end monosaccharide is accessible [44-46].

\section{Mass Spectrometry of Human Milk Oligosaccharides}

Human milk oligosaccharides represent a highly complex mixture. Two functions of these compounds are

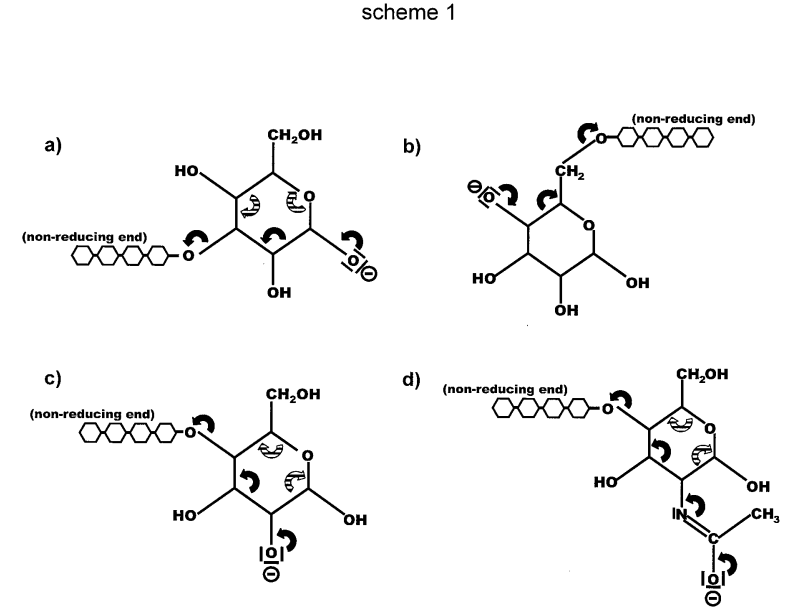

Scheme 1. Proposal for the consecutive C-type fragmentation pathway of deprotonated oligosaccharide subunits. The electronpair rearrangement is indicated with black arrows; the striped arrows describe alternative "routes" for the electron-pair rearrangement within the ring. In the case of such subunits that have a residue (i.e., sugar subunits up to the non-reducing end) in $\mathrm{O}(3)$-position (a), electron-pair rearrangement resulting in a Ctype fragment is directly possible. For $(1 \rightarrow 6)$ - and $(1 \rightarrow 4)$-linked oligosaccharide subunits [(b) and (c), respectively] a proton transfer prior to electron-pair rearrangement is necessary. For $\mathrm{N}$ acetylglucosamine subunits, deprotonation at the oxygen atom of the $\mathrm{N}$-acetyl-group in enol-form is assumed based on the observed fragment ions (d).

under discussion today: (1) These oligosaccharides promote the growth of certain beneficial gut bacteria (e.g., Bifidus ssp.), (2) they resemble soluble analogues of glycoconjugates (glycoproteins/glycolipids) of host and/or pathogen surfaces. Therefore, oligosaccharides are believed to prevent the adhesion of pathogens, which is a first step of the infection processes [47].

Up to now, 84 different oligosaccharide structures have been identified by FAB-MS and NMR [48-50]. As revealed by MALDI-MS [51, 52], human milk contains, besides some major components, large-size oligosaccharides up to $8000 \mathrm{Da}$ of so far unknown structure. The combination of high $\mathrm{pH}$ anion exchange chromatography with pulsed amperometric detection (HPAECPAD) $[53,54]$ and MALDI-MS proved to be a powerful tool for the analysis of human milk oligosaccharides with high sensitivity and no need of derivatization [52].

A detailed structural analysis is necessary for a further understanding of their function. In general, most of the human milk oligosaccharides consist of a few building blocks, i.e., lactose at the reducing end linked to multiple units of $\mathrm{N}$-acetyllactosamines, which differ in size, branching, and linkage, with additional fucose or sialic acid residues linked to the core oligosaccharides [47].

As the repetitive subunits and their structural features are known, structural analysis of human milk oligosaccharides must be addressed to the following aspects:

- Composition analysis. 
- Differentiation of the two core-constituents $N$-acetyllactosamine, i.e., Gal $\beta(1 \rightarrow 3)$ GlcNAc (LacNAc, lacto-series or "type I") and Gal $\beta(1 \rightarrow 4)$ GlcNAc (Lac-neo-NAc, lacto-neo-series or "type II").

- Determination of the position of fucose and/or sialic acid residues.

- Determination of branching positions.

The following is known and can be used for interpretation of the mass spectra:

- Linkage of the $N$-acetyllactosamine subunits (and the lactose to the first $N$-acetyllactosamine) is $(\beta 1 \rightarrow 3)$.

- Linkage of the fucose residues to $N$-acetylglucosamines depends on the linkage of the corresponding $N$-acetyllactosamine subunits: in the lacto-series, the fucose is $(\alpha 1 \rightarrow 4)$ linked and in the lacto-neoseries the linkage is $(\alpha 1 \rightarrow 3)$.

In principle, structural analysis of a given compound also includes the 3-dimensional structure; however, the term "structural analysis" in this paper refers exclusively to the features described above.

In this paper, structural analysis of neutral oligosaccharides from human milk oligosaccharides is demonstrated by $\mathrm{MS}^{\mathrm{n}}$ experiments of deprotonated molecules. The characteristics of the fragmentation behavior of deprotonated oligosaccharides from human milk are investigated with the goal to analyze unknowns even from complex isomeric mixtures (see part II) which are typically obtained by GPC fractionation of human milk oligosaccharides [52]. Recently, an ESI study of human milk oligosaccharides has been published, applying ESI-MS and a quadrupole-TOF hybrid instrument for MS/MS analysis. The results presented agree well with those reported here, however, they were based on a smaller selection of test compounds and fragmentation mechanisms have to be postulated, while they have been controlled and proven in this paper by using $\mathrm{MS}^{3}$ in the quadrupole ion-trap instrument [55].

\section{Experimental}

\section{Samples}

The separation of oligosaccharides from pooled human milk was performed using the following techniques: pasteurization, centrifugation, precipitation of proteins, preparative anion-exchange chromatography, HPLC chromatography, and GPC prefractionation; a more detailed description is given in [7, 52-54].

For mass analysis all samples were dissolved in deionized water, the oligosaccharide mixture to a total concentration of $1 \mathrm{~g} / \mathrm{L}$, all other oligosaccharides to a concentration of $1 \times 10^{-5} \mathrm{M}$. For formation of positive ions $\mathrm{NaCl}(10 \mathrm{mM})$ was added, 3:1 (vol:vol) to the mixture, 1:1 (vol:vol) to the other compounds. For negative-ion analysis ammonium acetate $\left(10^{-3} \mathrm{M}\right)$ was used as additive (3:1,vol:vol).
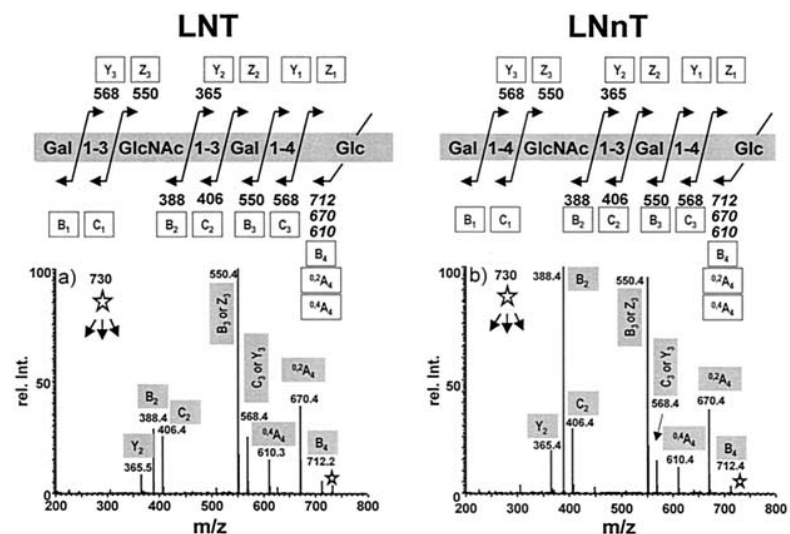

Figure 1. $\mathrm{MS}^{2}$ spectra of sodiated LNT (a) and LNnT (b) at $\mathrm{m} / \mathrm{z}$ 730 as precursor ions $(\star m / z 730)$. The observed fragment ions are explained in the structures above.

\section{Instrumentation}

For mass analysis and structure elucidation, a quadrupole ion trap mass spectrometer was used (LCQ, Finnigan MAT, San Jose, CA) equipped with a Nano-ESIsource (Protana, Odense, Denmark). The spray needles used were laboratory-pulled, gold-coated glass capillaries with an orifice diameter in the range of $1-2 \mu \mathrm{m}$. Typically 1-3 $\mu$ l of sample solution were loaded. The spray voltage was between $600-1200 \mathrm{~V}$, the transfer capillary was held at temperature of $200{ }^{\circ} \mathrm{C}$.

The LCQ [56] was used under standard settings, i.e., with a $\mathrm{q}_{\mathrm{z}}$-value of 0.9 . All mass spectra shown were acquired over a period of approximately $30 \mathrm{~s}$. For fragmentation by collision induced dissociation (CID) the relative collision energy in the QIT was set to $40-65 \%$ (corresponding to the LCQ software settings) depending on the charge and/or the chemical nature of the precursor ions. The precursor ion selection was carried out with an isolation width of $3 \mathrm{Da}$.

\section{Results}

\section{Positive Ion Mode}

Molecule ion species were subjected to fragmentation in positive and negative ion mode in order to check whether a differentiation between isomers is possible. In Figure 1 positive-ion mass spectra resulting from the fragmentation of the sodiated molecules of Lacto-NTetraose (LNT), (Figure 1a) and Lacto-N-neo-Tetraose (LNnT) (Figure 1b) at $m / z 730$ are compared (the structures of LNT and LNnT are also exhibited in Figure 1). The relative intensities of fragments originating from cleavage of the glycosidic bond between Lac and LacNAc, $\mathbf{B}_{2}(m / z 388)$ and $C_{2}(m / z 406)$, are different. The intensities of $B_{2}$ and $C_{2}$ are equal in the spectrum of LNT, whereas for LNnT the intensity of $B_{2}$ is much higher than $\mathrm{C}_{2}$. Although there is no difference in the nature of the bond cleaved, the resulting fragment disaccharides differ in linkage of the monosaccharide subunits. Since the remaining $N$-acetyllactosamine sub- 


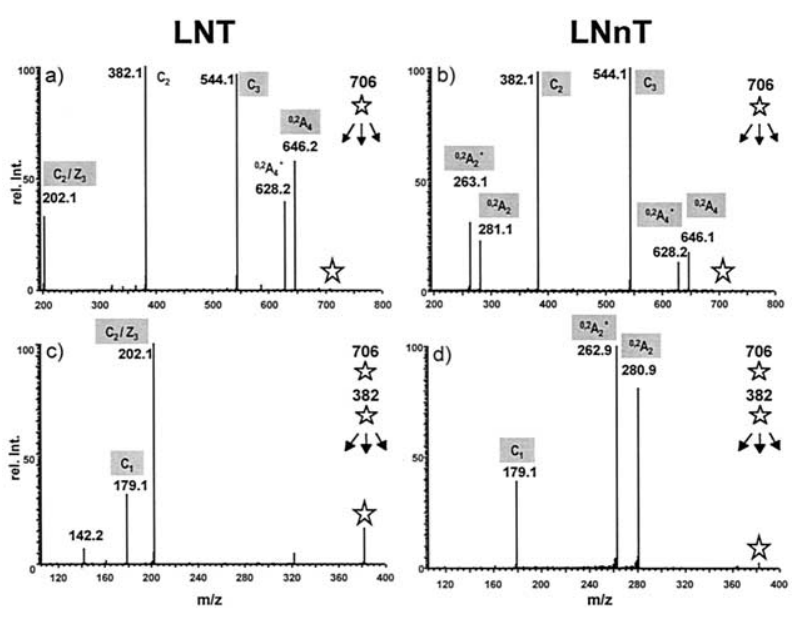

Figure 2. $\mathrm{MS}^{2}$ spectra of deprotonated LNT (a) and LNnT (b) at $m / z 706$ as precursor ion $(\star m / z 706)$. MS ${ }^{3}$ spectra of LNT (c) and LNnT (d) with $m / z 382$ as precursor ion ( $\star m / z 706 \star m / z$ 382). For further information see text.

unit is $(1 \rightarrow 3)$-linked in the case of LNT, the signal intensity of the $B_{2}$ fragment ion is reduced by an additional loss of the galactose $(\Delta \mathrm{m}=180 \mathrm{Da})$, which is suggested to occur via a $\beta$-elimination [57] (see below). The schematic explanation of the observed fragment ions are given in the insert of Figure 1. However, it is questionable whether this method based on signal intensities alone is reliable for larger oligosaccharides.

\section{Negative Ion Mode}

$\mathrm{MS}^{\mathrm{n}}$ investigations in the negative-ion mode yield unambiguous structural information for oligosaccharides, even for larger ones, as shown below. Under the chosen experimental conditions exclusively deprotonated molecules $[\mathrm{M}-\mathrm{H}]^{-}$are detected, which are most probably formed by the loss of acetic acid from initial acetateattached ions $\left[\mathrm{M}+\mathrm{CH}_{3} \mathrm{COO}\right]^{-}$or $\mathrm{HCl}$ from $[\mathrm{M}+\mathrm{Cl}]^{-}$ ions, respectively [45].

\section{Differentiation of Isomeric Structures, Linkage Analysis}

Figure $2 \mathrm{a}$ and $\mathrm{b}$ show the $\mathrm{MS}^{2}$ spectra of the deprotonated ions of LNT and LNnT ( $\star m / z$ 706); explanations for the observed fragment ions are given as inserts. Both compounds produce cross-ring fragments of the $1 \rightarrow 4$ linked glucose as well as C-type fragment ions resulting in the loss of two hexoses (solid lines). The exclusive (consecutive) formation of C-type ions and the interpretation of the mass spectra based on this fact is described in detail in the Discussion section.

Only Lac-neo-NAc (found in LNnT) exhibits further cross-ring fragment ions ${ }^{0,2} \mathrm{~A}_{2}$ with $\mathrm{m} / \mathrm{z} 281$ (loss of 101 Da) and a further loss of $\mathrm{H}_{2} \mathrm{O}$, indicated with ${ }^{0,2} \mathrm{~A}_{2}{ }^{*}$, at $\mathrm{m} / \mathrm{z} 263$ (loss of $119 \mathrm{Da}$ ); this could be verified by $\mathrm{MS}^{3}$ experiments of the $C_{2}$ fragment at $m / z 382$ (see Figure 2c and d) $(\star m / z 706 \star m / z$ 382). The observed fragmen-

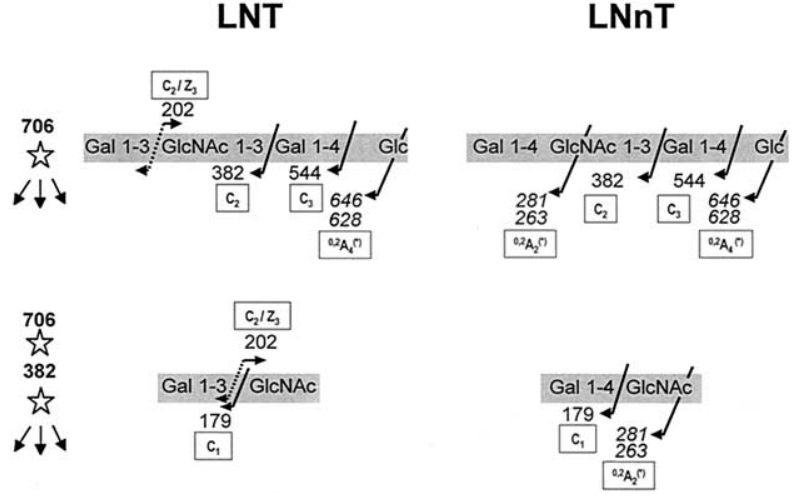

Figure 3. Schematic explanation of the origin of the observed fragment ions in $\mathrm{MS}^{2}$ and $\mathrm{MS}^{3}$ experiments of LNT and LNnT (compare to Figure 2).

tations are illustrated in Figure 3. In contrast to LNnT, the $(1 \rightarrow 3)$-linked terminal Gal in LNT is eliminated $(\Delta \mathrm{m}$ $=180 \mathrm{Da})$, resulting in the $\mathrm{C}_{2} / \mathrm{Z}_{3}$ fragment ion with $\mathrm{m} / \mathrm{z}$ 202 (dotted line). This fragmentation pathway is specific for $1 \rightarrow 3$-linkages and will gain importance for the determination of fucose linkage as discussed.

The suitability of this method for linkage determination of larger oligosaccharides is demonstrated by investigation of Lacto-N-para-Hexose (LNparaH), a linear hexasaccharide. Figure 4 a shows the negative-ion $\mathrm{MS}^{2}$ spectrum from fragmentation of the deprotonated molecule $(\star m / z$ 1071), which exhibits predominant fragment ions of the C-type series $\left(\mathrm{C}_{5}: \mathrm{m} / \mathrm{z} 909(\Delta \mathrm{m}=162\right.$ Da), $\mathrm{C}_{4}: m / z 747(\Delta \mathrm{m}=162 \mathrm{Da}), \mathrm{C}_{3}: m / z 544(\Delta \mathrm{m}=203$ $\mathrm{Da}), \mathrm{C}_{2}: m / z 382(\Delta \mathrm{m}=162 \mathrm{Da})$, indicating the sequence from the reducing end: (Hex + HexNAc)-Hex-HexNAc-Hex-Hex (the remaining fragment ion at $m / z 382$ indicates the presence of a (Hex $+\mathrm{HexNAc})$ at the non-reducing end). This can be translated to LacNacLacNAc-Lac for human milk oligosaccharides. The cross-ring fragment ions at $m / z 1011$ and 993 indicate a $1 \rightarrow 4$-linkage of the reducing glucose $\left({ }^{0,2} \mathrm{~A}_{6}^{*}\right)$, and the

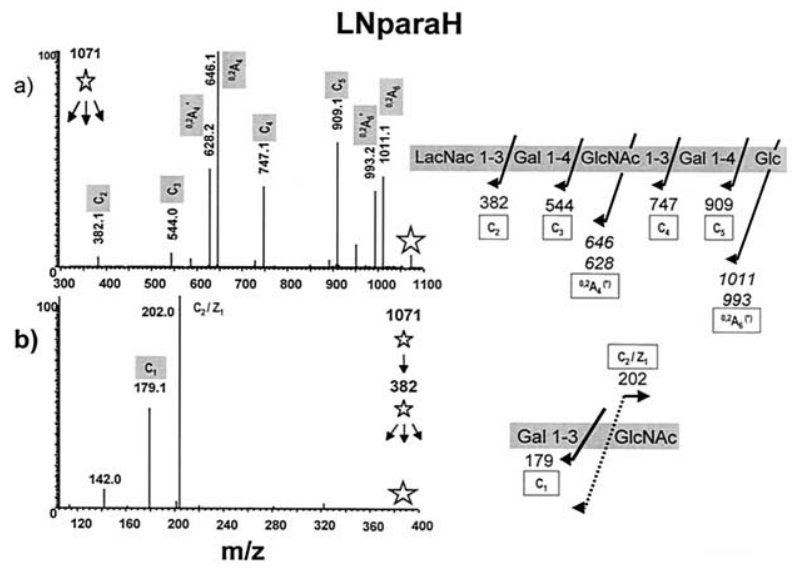

Figure 4. $\quad \mathrm{MS}^{\mathrm{n}}$ spectra of the deprotonated LNparaH. (a) shows the $\mathrm{MS}^{2}$ spectrum with $\mathrm{m} / \mathrm{z} 1071$ as precursor ion and the schematic explanation of the observed fragment ions; the $\mathrm{MS}^{3}$ spectrum with $m / z 382(\star m / z 1071 \star m / z 382)$ as well as the schematic explanation of the observed fragment ions is demonstrated in (b). 

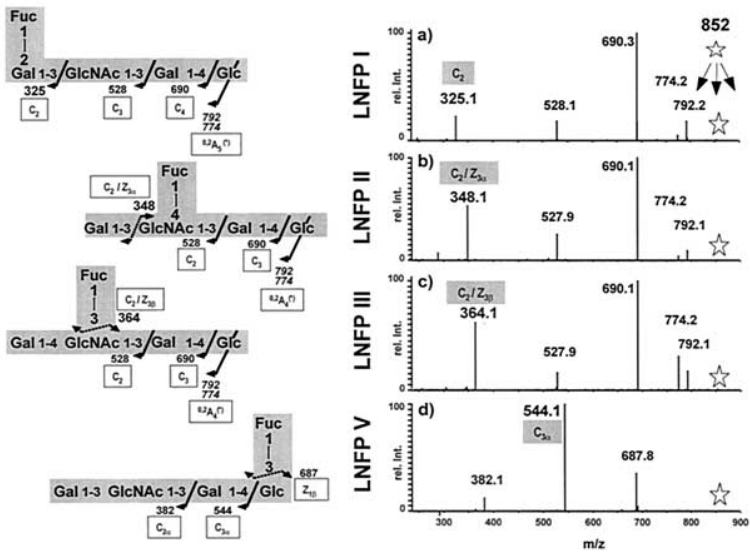

Figure 5. MS ${ }^{2}$ spectra of deprotonated LNFP I (a), LNFP II (b), LNFP III (c), and LNFP V (d) at $m / z 852$ as precursor ion $(\star \mathrm{m} / \mathrm{z}$ 852). The schematic explanation of the observed fragment ions is given on the left hand side of the mass spectra. For further discussion see text.

fragment ions at $\mathrm{m} / \mathrm{z} 646$ and 628 reveal the linkage of the LacNac-subunit as $1 \rightarrow 4$ as well. The absence of fragment ions between $\mathrm{m} / \mathrm{z} 909$ and 747 as well as between $\mathrm{m} / \mathrm{z} 544$ and 382 is due to the $1 \rightarrow 3$-linkage between the LacNAc-units. Figure $4 \mathrm{~b}$ shows the $\mathrm{MS}^{3}$ spectrum of the $C_{2}$ fragment ion at $m / z 382(\star m / z 1071$ $\star m / z$ 382). The additional $\mathrm{MS}^{3}$ step is necessary, because the $\mathrm{m} / \mathrm{z}$ range for $\mathrm{MS}^{2}$ spectra in the QIT instrument is limited to approximately $25 \%$ of the precursor ion $\mathrm{m} / \mathrm{z}$. The comparison of this spectrum with the MS ${ }^{3}$ of $C_{2}$ ion of LNT (see Figure 2c and discussion above) reveals, that the remaining unit is LacNAc of the lacto-series, i.e., Gal $\beta 1 \rightarrow 3$ GlcNAc.

In conclusion, both sequence and linkage information of the oligosaccharide can be obtained from the $\mathrm{MS}^{\mathrm{n}}$-spectra $(n \leq 3)$ for this (linear) hexose.

\section{Determination of the Position and Linkage Type of Fucoses}

In contrast to CID of positive $\left([\mathrm{M}+\mathrm{Na}]^{+}\right)$ions [41], deprotonated ions show a high stability of the fucose linkages, a prerequisite for determination of their position. Furthermore, as the formation of C-fragments is the predominant fragmentation, the ambiguity of the masses of $\mathrm{Y} / \mathrm{C}$ and $\mathrm{B} / \mathrm{Z}$ fragments of sodiated underivatized oligosaccharides no longer exists. Four structural isomers of Lacto-N-Fucopentaoses (LNFP), LNFP I (Figure 5a), LNFP II (Figure 5b), LNFP III (Figure 5c) and LNFP V (Figure 5d) were analyzed by ESI-MS ${ }^{2}$ ( $\star$ $\mathrm{m} / \mathrm{z}$ 852) to determine the position of fucoses. Each molecule yields a characteristic fragmentation pattern in the negative-ion mode, the position of fucose can unambiguously be determined. Explanations for the origins of the observed fragment masses are also given in Figure 5.

The fragment ions for the linear LNFP I can be explained as a C-type ion series $\left(\mathrm{C}_{4}: \mathrm{m} / z\right.$ 690, $\mathrm{C}_{3}: \mathrm{m} / \mathrm{z} 528$ and $C_{2}: m / z$ 325) accompanied by the typical ring fragment ions ${ }^{0,2} \mathrm{~A}_{5}^{(*)}$ of the $\beta 1 \rightarrow 4$-linked reducing glucose with $\mathrm{m} / \mathrm{z} 792$ and $\mathrm{m} / \mathrm{z} 774$.

In contrast to LNFP I, the fucose residues in LNFP II, LNFP III, and LNFP V form a branched structure. Nevertheless, no unselective loss of the fucoses is observed for those fucoses as well, as described below.

The $\mathrm{MS}^{2}$ spectrum of the deprotonated LNFP II shows (despite the ring fragment ions ${ }^{0,2} \mathrm{~A}_{4}^{(*)}$ of the $\beta 1 \rightarrow 4$-linked reducing glucose with $m / z 792$ and 774) the prominent fragment ions with $\mathrm{m} / \mathrm{z} 690,528$ and 348 . Whereas the first two are consecutive C-type losses $\left(\mathrm{C}_{4}\right.$ and $C_{3}$, respectively), the latter fragment ion, $\mathrm{m} / \mathrm{z} 348$, results from a consecutive loss $\left(C_{2} / Z_{3 \alpha}\right)$ of the terminal galactose from fragment ion $\mathrm{C}_{2}$. The $\alpha 1 \rightarrow 4$-linked fucose (attached to the GlcNAc) remains stable, while the $\beta 1 \rightarrow 3$-linkage of the galactose cleaves due to $\beta$-elimination.

The $\mathrm{MS}^{2}$ spectrum of the deprotonated molecule of LNFP III shows the prominent fragment ions with $\mathrm{m} / \mathrm{z}$ $690\left(C_{3}\right), m / z 528\left(C_{2}\right)$, and $m / z 364\left(C_{2} / Z_{3 \alpha}\right)$, again accompanied by the ring fragment ions ${ }^{0,2} \mathrm{~A}_{4}^{(*)}$ of the $\beta 1 \rightarrow 4$-linked reducing glucose with $m / z 792$ and 774 . Again, $m / z 690$ and 528 are formed by consecutive C-type cleavages $\left(C_{4}\right.$ and $C_{3}$, respectively). As the fucose in this isomer is attached to the GlcNAc in a (relatively unstable) $\alpha 1 \rightarrow 3$-linkage, the $\mathrm{C}_{2} / \mathrm{Z}_{3 \alpha}$ fragment ion is formed by a consecutive loss from the $C_{2}$ fragment ion by elimination of fucose $(\Delta \mathrm{m}=164 \mathrm{Da})$ resulting in $\mathrm{m} / \mathrm{z} 364$, as indicated by the lack of a fucose loss from $\mathrm{C}_{3}$.

The fucose in LNFP V is attached to the reducing glucose in a $\alpha 1 \rightarrow 3$-linkage, therefore, the typical ring fragment ions of this glucose (compare to the structures described above) can be observed in the $\mathrm{MS}^{2}$ spectrum of this isomer. Three fragment ions can be observed, $\mathrm{m} / \mathrm{z}$ $688\left(\mathrm{Z}_{1 \beta}\right), m / z 544\left(\mathrm{C}_{3 \alpha}\right)$ and $m / z 382\left(\mathrm{C}_{2 \alpha}\right)$. The fragment ion with $\mathrm{m} / \mathrm{z} 688$ is formed by a loss of $164 \mathrm{Da}$, i.e., by elimination of fucose as observed in LNFP II.

Each LNFP isomer shows characteristic fragment ions which can be used as diagnostic ions, such as $\mathrm{m} / \mathrm{z}$ 325 for LNFP I, $m / z 348$ for LNFP II, $m / z 364$ for LNFP III, and $m / z 544$ (or the less abundant $m / z$ 688) for LNFP $\mathrm{V}$. These findings have also been demonstrated by König et al. [35].

The structural analysis and thus differentiation of more complex, fucosylated isomers is possible as exhibited for LNDFH I (Figure 6a) and LNFP II (Figure 6b). Again, both sequence and linkage analysis can be carried out, as shown in the schematic explanations in Figure 6 (compare also to discussions above and Table $1)$.

\section{Determination of Branching Sites}

Furthermore, the fragmentation behavior of deprotonated branched isomeric structures has been investigated (see Figure 9). As test compounds LNH and LNnH were used, which only differ in one glycosidic 
LNDFH I
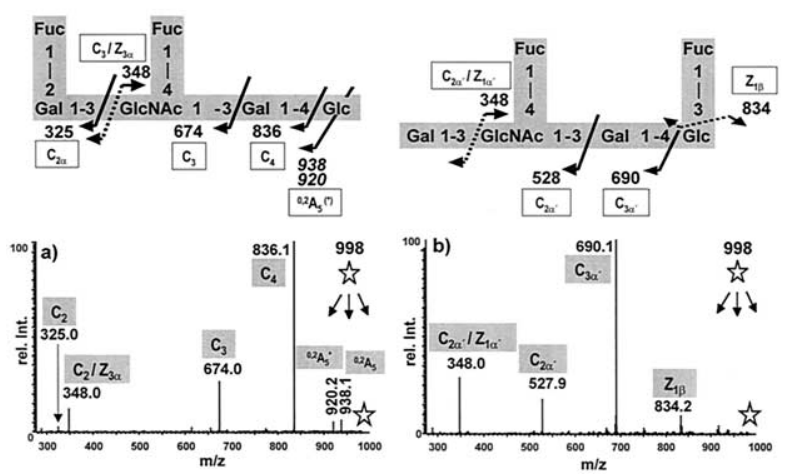

Figure 6. MS ${ }^{2}$ spectra of the deprotonated molecules $(\star m / z$ 998) of the difucosylated structures LNDFH I (a) and LNDFH II (b). The observed fragment ions are explained in the schematic structures above the spectra.

linkage of a LacNAc subunit in their " $1 \rightarrow 3$-branch". LNH contains a LacNAC of the Lacto-series (Gal $\beta 1 \rightarrow 3$ GlcNAc), whereas LNnH comprises a Lac-neo-NAc subunit (Gal $\beta 1-4$ GlcNAc). However, the $\mathrm{MS}^{\mathrm{n}}$-spectra $(n=$
$2,3,4)$ of these two compounds are identical. Figure 7a shows the MS ${ }^{2}$ spectrum of LNH $(\star m / z$ 1071).

The MS ${ }^{3}$ mass spectrum of the $\mathrm{C}_{3}$ fragment ion with $m / z 909$ as precursor ion $(\star m / z 1071 \star m / z 909$, see Figure $7 \mathrm{~b}$ ) shows a big gap, which cannot be observed in linear structures (compare LNparaH, Figure 4a and b), resulting in a molecular ion with $m / z 526$ (i.e., loss of $383 \mathrm{Da})$. This is the result of an elimination of a $N$-acetyllactosamine subunit $(\Delta \mathrm{m}=383 \mathrm{Da})$, i.e., a $\mathrm{C}_{3} / \mathrm{Z}_{2 \alpha}$ fragment ion.

Further $\mathrm{MS}^{\mathrm{n}}$ experiments were addressed to the question which branch, $1 \rightarrow 6$ or $1 \rightarrow 3$ LacNAc, is eliminated. $\mathrm{MS}^{3}$ of the $\mathrm{C}_{3} / \mathrm{Z}_{2 \alpha}$ fragment ion with $m / z 526$ as precursor $(\star m / z 1071 \star m / z 526$, see Figure 7c) shows a mass increment of $144 \mathrm{Da}$ accompanied by a further loss of $\star \mathrm{Da}$, as well as the characteristic fragment ions produced by a Lac-neo-Nac subunit, $m / z 281,263$ and 179 (compare to $\mathrm{MS}^{3}$ of LNT, see Figure 2c), a fact, which is confirmed by the MS ${ }^{4}$ spectrum of the $C_{2 \beta}$ fragment with $m / z 382(\star m / z 1071 \star m / z 526 \star m / z 382$, see Figure $7 \mathrm{~d}$ ). The $\mathrm{MS}^{3}$ and $\mathrm{MS}^{4}$ spectra of both isomers yield identical fragment ions, which shows that the $1 \rightarrow 3$ branch causes the elimination.

Table 1. Fragmentation behavior of deprotonated human-milk oligosaccharides. Characteristic mass increments and their meaning for the analysis of human-milk oligosaccharides

\begin{tabular}{|c|c|c|c|}
\hline Analysis & $\begin{array}{l}\text { Mass increment } \\
\text { (Da) }\end{array}$ & Interpretation & Assignment \\
\hline \multirow[t]{8}{*}{ Sequence } & 162 & $\begin{array}{l}\text { Cleavage of hexose (Hex- } \\
\left.\qquad \mathrm{H}_{2} \mathrm{O}\right)\end{array}$ & - $1^{\text {st }}$ loss $=$ glucose \\
\hline & 203 & $\begin{array}{l}\text { Cleavage of HexNAc } \\
\quad\left(\text { GlcNAc- } \mathrm{H}_{2} \mathrm{O}\right)\end{array}$ & $\begin{array}{l}\text { - Further losses = galactoses } \\
\text { HexNAc = GIcNAc }\end{array}$ \\
\hline & $\begin{array}{c}308 \\
(146+162)\end{array}$ & $\begin{array}{l}\text { Fucose residue on } \\
\quad \text { hexose }\left(\mathrm{Hex}+\mathrm{Fuc}-\mathrm{H}_{2} \mathrm{O}\right)\end{array}$ & - $(1 \rightarrow 3)$ Linked fucose on Glc \\
\hline & & & $\begin{array}{l}\text { - }(1 \rightarrow 2) \text { Linked fucose on Gal } \\
\text { - In case of }(1 \rightarrow 3) \text {-linked fucoses in combination with loss of } 164 \mathrm{Da}\end{array}$ \\
\hline & $\begin{array}{c}349 \\
(146+203)\end{array}$ & $\begin{array}{l}\text { Fucose residue on } \\
\text { HexNAc (HexNAc+Fuc) }\end{array}$ & $\bullet(1 \rightarrow 3)$-linkage (lacto-neo) or $(1 \rightarrow 4)$-linkage (lacto) \\
\hline & 185 & $\begin{array}{l}\text { Cleavage of "anhydro" } \\
\text { HexNAc }\left(\mathrm{GlcNAc}-2 \mathrm{H}_{2} \mathrm{O}\right)\end{array}$ & $\begin{array}{l}\text { - In case of }(1 \rightarrow 3) \text {-linked fucoses in combination with loss of } 164 \mathrm{Da} \\
\text { - This GlcNAc was linked to a fucose in position 3, i.e. Lac-neo-Nac }\end{array}$ \\
\hline & 144 & $\begin{array}{l}\text { Cleavage of "anhydro" } \\
\text { hexose }\left(\mathrm{Gal}-2 \mathrm{H}_{2} \mathrm{O}\right)\end{array}$ & - Branching site \\
\hline & & & - Often in combination with ring fragment $-72 \mathrm{Da}$ \\
\hline \multirow[t]{5}{*}{ Linkage } & $\begin{array}{l}\text { No ring } \\
\text { fragments }\end{array}$ & $\begin{array}{l}(1 \rightarrow 3) \text {-linkage of the } \\
\text { monosaccharide } \\
\text { subunit "above" }\end{array}$ & $\begin{array}{l}\text { - Observed either between a) LacNAc-subunits or b) Gal and GlcNac } \\
\text { in the lacto-neo-series }\end{array}$ \\
\hline & $60 / 78$ & $(1 \rightarrow 4)$-linked hexose & $\begin{array}{l}\text { - Exclusively observed at the reducing end: }(1 \rightarrow 4) \text {-linked glucose in } \\
\text { lactose }\end{array}$ \\
\hline & $101 / 119$ & $(1 \rightarrow 4)$-linked GlcNAc & - Lac-neo-LacNAc \\
\hline & 164 & $\begin{array}{l}\text { Elimination of }(1 \rightarrow 3)- \\
\text { linked fucose (Fuc) }\end{array}$ & - At Glc or GlcNAc, i.e. GlcNAc is $(1 \rightarrow 4)$-linked (lacto-neo-series) \\
\hline & 72 & $\begin{array}{l}\text { Gal-2 } \mathrm{H}_{2} \mathrm{O} \text { at branching } \\
\text { site }\end{array}$ & $\begin{array}{l}\text { - Characteristic ring fragment of a }(1 \rightarrow 6) \text {-linked "anhydro" galactose- } \\
\mathrm{H}_{2} \mathrm{O} \text {, which lost a }(1 \rightarrow 3) \text {-branch } \\
\text { - Often in combination with loss of } 18 \mathrm{Da} \text { and } 144 \mathrm{Da}\end{array}$ \\
\hline \multirow[t]{2}{*}{ Branching } & $\begin{array}{l}\{\mathrm{n}(365) \\
+\mathrm{a}(146) \\
\quad+18\}\end{array}$ & $\begin{array}{l}\text { Branching site; } \mathrm{n} \text { and a } \\
\text { determine composition } \\
\text { of the branch }\end{array}$ & - Deprotonated reducing end is a "anhydro" galactose $\left(\mathrm{Gal}-2 \mathrm{H}_{2} \mathrm{O}\right)$ \\
\hline & $\begin{array}{l}\mathrm{n}=1,2,3 \ldots \\
\mathrm{a}=0,1,2 \ldots\end{array}$ & & $\begin{array}{l}\text { - In combination with characteristic ring fragments (-18 Da and } 72 \\
\text { Da) }\end{array}$ \\
\hline
\end{tabular}




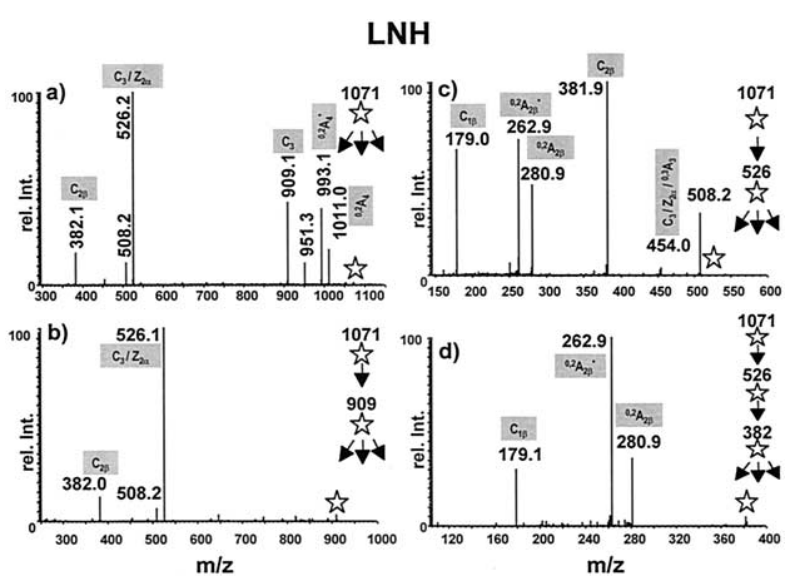

Figure 7. $\mathrm{MS}^{\mathrm{n}}$ spectra of the deprotonated molecules of the branched structure LNH. (a shows the $\mathrm{MS}^{2}$ spectrum with $\mathrm{m} / \mathrm{z}$ 1071 as precursor ion. (b and $\mathbf{c}$ show the MS ${ }^{3}$ spectra with $m / z 909$ [ $\star m / z 1071 \star m / z$ 909, (b)] and $m / z 526$ [ $\star m / z 1071 \star m / z 526$, (c)] as precursor ions. The MS ${ }^{4}$ spectrum with $\mathrm{m} / \mathrm{z} 382(\star \mathrm{m} / \mathrm{z} 1071 \star$ $\mathrm{m} / \mathrm{z} 526 \star \mathrm{m} / \mathrm{z} 382$ ) as precursor ion is demonstrated in (d). The $\mathrm{MS}^{\mathrm{n}}$ spectra of the deprotonated LNnH reveal identical fragment ions. For further discussion see text.

To prove this, the deprotonated molecule of TFLNH (mass spectra in Figure 8, for structure please refer to Figure 9) was investigated in $\mathrm{MS}^{\mathrm{n}}$ experiments $(\star \mathrm{m} / \mathrm{z}$ 1509). This standard was chosen, because the two branches of this molecule contain a different number of fucoses: whereas one fucose is attached to the $1 \rightarrow 6$ branch, the $1 \rightarrow 3$ branch contains two fucoses. The mass increment of $675 \mathrm{Da}$ in the $\mathrm{MS}^{2}$ spectrum (Figure $8 \mathrm{a}, \mathrm{m} / \mathrm{z}$ 1509 as precursor ion) and the $\mathrm{MS}^{3}$ spectrum with $\mathrm{m} / \mathrm{z}$ $1347\left(C_{4}, \star m / z 1509 \star m / z ~ 1347\right.$, see Figure 8b), respectively, is caused by the elimination of the $1 \rightarrow 3$ branch ( $\mathrm{LacNAc}+2 \mathrm{Fuc}+\mathrm{H}_{2} \mathrm{O}=365+2 \cdot 146+18=$ $675 \mathrm{Da})$. Again, the $\mathrm{MS}^{3}$ spectrum of $m / z 672\left(\mathrm{C}_{4} / \mathrm{Z}_{3 \alpha}\right.$, $\mathrm{m} / \mathrm{z} 1509$, see Figure 8c) shows a mass increment of 144 $\mathrm{Da}\left(\mathrm{C}_{2 \beta^{\prime}}\right)$ and a further loss of $72 \mathrm{Da}\left(\mathrm{C}_{4} / \mathrm{Z}_{3 \alpha} /{ }^{0,3} \mathrm{~A}_{4}\right)$. These results reveal clearly, that this neutral loss is caused by the elimination of the $1 \rightarrow 3$ branch. The explanations for the observed fragment masses of $\mathrm{LNH}$, $\mathrm{LNnH}$ and TFLNH in the $\mathrm{MS}^{\mathrm{n}}$ experiments are given in Figure 9 .

\section{Discussion}

\section{C-Type Fragmentation Pathway}

As described above, only consecutive C-type fragments are observed in CID-MS ${ }^{n}$ experiments of $[\mathrm{M}-\mathrm{H}]^{-}$-ions of human milk oligosaccharides; no internal fragments (i.e., losses from both sides the reducing and the nonreducing end) are observed. The exclusive occurrence of C-type fragmentation can be substantiated by the following considerations. As an example, Figure 10a shows the possible fragment ion masses of deprotonated LNT or LNnT (for mass spectra refer to Figure 2). From the complete absence of $m / z 526,364,323$, and 161 it can be deduced, that no B- or Z-type fragmentations occur if deprotonated (neutral) oligosaccharides from human milk are investigated in $\mathrm{MS}^{\mathrm{n}}$ experiments (a combination of $\mathrm{C} / \mathrm{Z}$ fragmentation is e.g., observed if branching occurs on the resulting consecutive $C$-fragment as described below in detail). Furthermore, the absence of $m / z 341\left(\mathrm{Y}_{2}\right)$ gives evidence that, like $\mathrm{B}$ and $\mathrm{Z}$, also Y-type fragmentation does not occur in deprotonated (neutral) human milk oligosaccharides. As, in principle, $m / z 544$ also may correspond to a $Y_{3}$ ion, this fragment ion was investigated in a $\mathrm{MS}^{3}$ experiment to determine wether $\mathrm{m} / \mathrm{z} 544$ is a $\mathrm{C}_{3}$ or a $\mathrm{Y}_{3}$ ion (or a mixture of both). Figure $10 \mathrm{~b}$ shows the $\mathrm{MS}^{3}$ spectra of (deprotonated) LNT and LNnT with $m / z 544$ as precursor ion $(\star m / z 706 \star m / z 544)$; the inserts below describe the structures of the two possibilities, i.e., $\mathrm{C}_{3}$ and $\mathrm{Y}_{3}$ fragment ions. First, as the structures of the $Y_{3}$ fragment ions of LNT and LNnT are identical, one would expect identical MS ${ }^{3}$ spectra of LNT and LNnT, but different ones are observed. Second, both the $C_{3}$ and the $Y_{3}$ fragment ions may produce $m / z 382$ and 179 , but only $\mathrm{C}_{3}$ is able to generate (in the case of LNnT) the crossring fragments with $\mathrm{m} / \mathrm{z} 280$ and 263 (as indicated in Figure $10 \mathrm{~b}$ ). Furthermore, if $m / z 544$ would be $\mathrm{B}_{3}$ or a mixture of both the $\mathrm{C}_{3}$ and $\mathrm{B}_{3}$, cross-ring fragments of the reducing $1 \rightarrow 4$-linked glucose with $\mathrm{m} / \mathrm{z} 484$ and 466 should be observed. As this is not the case, it can be concluded that $\mathrm{m} / \mathrm{z} 544$ is exclusively a C-type ion. Additional $\mathrm{MS}^{\mathrm{n}}$-experiments with different isomers (e.g., LNparaH) have been addressed to the same question; the results reveal that the $\mathrm{MS}^{\mathrm{n}}$ spectra of deprotonated oligosaccharides from human milk show in general exclusively C-type fragmentation.

Therefore, we suggest a simple fragmentation pathway based on the assumption, that the deprotonation is localized at the most acidic $\mathrm{OH}$-group, the anomeric $\mathrm{OH}$ at the reducing end. It occurs via an electron pair rearrangement which either takes place from the reducing end in the pyranose or open chain form, but the ring-opening is, in contrast to ring-fragmentation, not necessary. As indicated in Scheme 1, for some linkages a proton transfer has to occur prior to electron pair rearrangement.

In general, for linear structures no losses of $1 \rightarrow 3-$ linked subunits are observed; only in the case of a remaining $1 \rightarrow 3$-linked disaccharide both the characteristic C-type fragmentation and the elimination of the nonreducing-end monosaccharide subunit are observed. $1 \rightarrow 3$-linked branches show a neutral loss by elimination (in-chain mass $+18 \mathrm{Da}$ ): This only occurs at a deprotonated reducing end unit (C-type ion). C-type fragmentation competes with ring fragmentation. In the case of $1 \rightarrow 3$-linked branches, the C-type fragmentation of the corresponding monosaccharide subunit is in competition with the elimination of the branching site. Scheme 1 demonstrates the suggested fragmentation pathway for hexoses with residues in $\mathrm{O}(3)-, \mathrm{O}(4)$ - and $\mathrm{O}(6)$ - position and a $\mathrm{N}$-acetylhexose with a residue in $\mathrm{O}(4)$-position. 

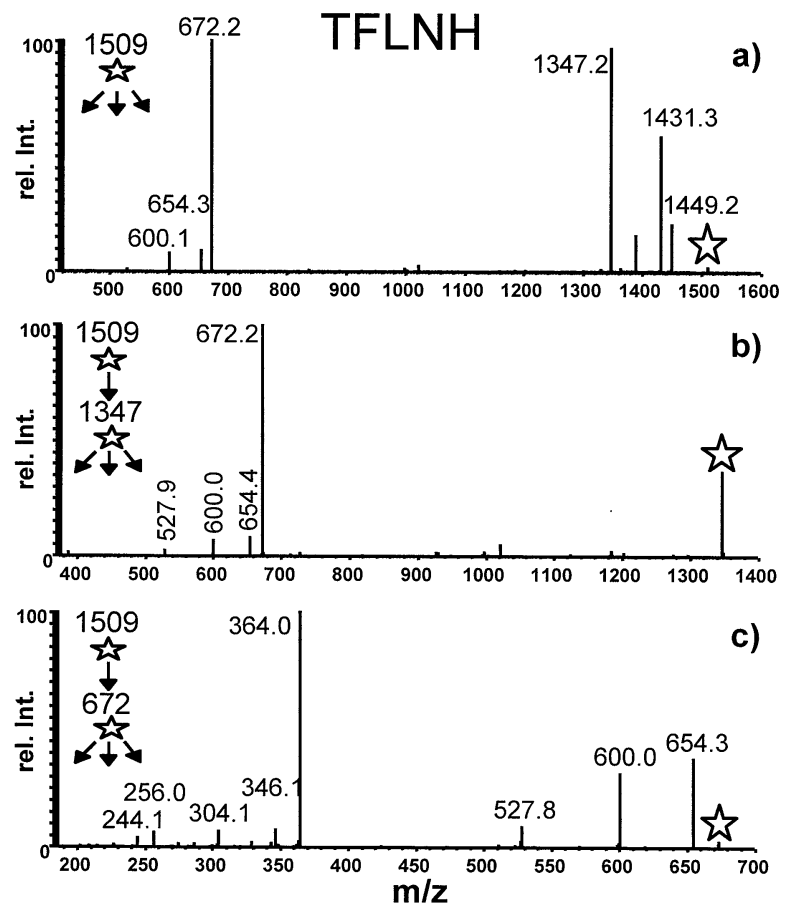

Figure 8. $\mathrm{MS}^{\mathrm{n}}$ spectra of $[\mathrm{M}-\mathrm{H}]^{-}$of the trifucosylated, branched structure TFLNH. (a) shows the $\mathrm{MS}^{2}$ spectrum with $\mathrm{m} / \mathrm{z}$ 1509 as precursor ion, (b) and (c) show the MS ${ }^{3}$ spectra with $\mathrm{m} / \mathrm{z}$ $1347[\star m / z 1509 \star m / z ~ 1347,(b)]$ and $m / z 672[\star m / z ~ 1509 \star m / z$ $672,(\mathrm{c})]$ as precursor ions. For further information see text.

The fundamental fragmentation rules of deprotonated oligosaccharides from human milk are summarized in the following. Fragmentation of negatively charged oligosaccharides occurs exclusively from the reducing end of the sugar and leads to subsequent C-type losses of the sugar units accompanied by crossring cleavages which are characteristic for a given linkage type [45].

By fragmenting $[\mathrm{M}-\mathrm{H}]^{-}$-ions of isomeric glycoforms with distinct structural features, fragmentation rules could be deduced which provide a means for structural analysis of neutral human milk oligosaccharides based on already known possible linkages of these sugars (given in the introduction). The fragmentation rules and the arising incremental molecular masses are summarized in Table 1.

$\mathrm{MS}^{\mathrm{n}}$ spectra of deprotonated oligosaccharides can be read "from right to left", paying attention to distinct mass increments. Glycosidic bond cleavage (see Table 1) occurs exclusively as C-type cleavage of monosaccharide subunits and leads to the loss of either $162 \mathrm{Da}$ (loss of a Hex- $\mathrm{H}_{2} \mathrm{O}$, i.e., glucose or galactose $=$ in-chain mass) or $203 \mathrm{Da}$ (loss of a $\mathrm{N}$-acetylglucosamine, GlcNAc- $\mathrm{H}_{2} \mathrm{O}$ $=$ in-chain mass). These may be fucosylated (308 Da or $349 \mathrm{Da}$, respectively) or occur in combination with a further loss of $\mathrm{H}_{2} \mathrm{O}$ (144 Da and $\left.185 \mathrm{Da}\right)$. Unlike sodiated ions, $[\mathrm{M}-\mathrm{H}]^{-}$-ions show a relatively high stability towards the loss of fucose residues. Unselective loss of fucose as typically observed in the positive-ion mode does not occur. For instance, $1 \rightarrow 3$-linked fucoses
LNH or LNnH

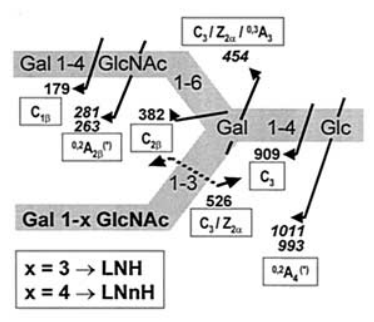

TFLNH

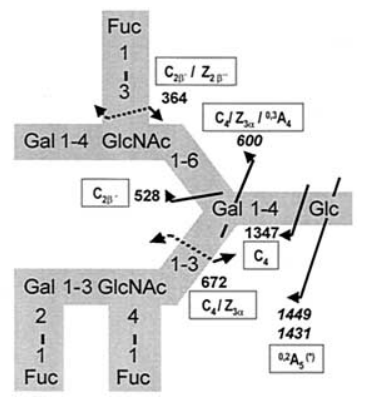

Figure 9. Schematic explanations of the origin of the observed fragment ions in $\mathrm{MS}^{2}$ up to $\mathrm{MS}^{4}$ experiments of $\mathrm{LNH}(\mathrm{x}=3$, compare to Figure 7), $\mathrm{LNnH}(\mathrm{x}=4)$ and TFLNH (compare to Figure 8).

at $\mathrm{N}$-acetylglucosamine residues are only cleaved off, if this GlcNAc is the deprotonated "new" reducing end; due to elimination of the fucose an accompanying incremental mass of $185 \mathrm{Da}$ (loss of GlcNAc- $2 \mathrm{H}_{2} \mathrm{O}$ ) is observed. This also means, that the fucosylated subunit must have been a LacNac of the lacto-neo-series $(1 \rightarrow 4-$ linkage), even though no typical ring fragments can be observed (see below). On the other hand, a stable $1 \rightarrow 4$-linked fucose on a $\mathrm{N}$-acetyl-lactosamine gives an incremental molecular mass of $349 \mathrm{Da}$; therefore, this LacNAc belongs to the lacto-series ( $1 \rightarrow 3$-linkage).

The occurrence of characteristic cross-ring fragments (see Table 1) yielding signals "between" the monosaccharide subunits give information about the linkages in the molecule. For instance, 60 and $78 \mathrm{Da}$ losses are typical for a $(1 \rightarrow 4)$-linked hexose as present in lactose, while $(1 \rightarrow 4)$-linked $N$-acetylglucosamines show losses of 101 and 119 Da from the $C_{2}$-type ion. The lack of

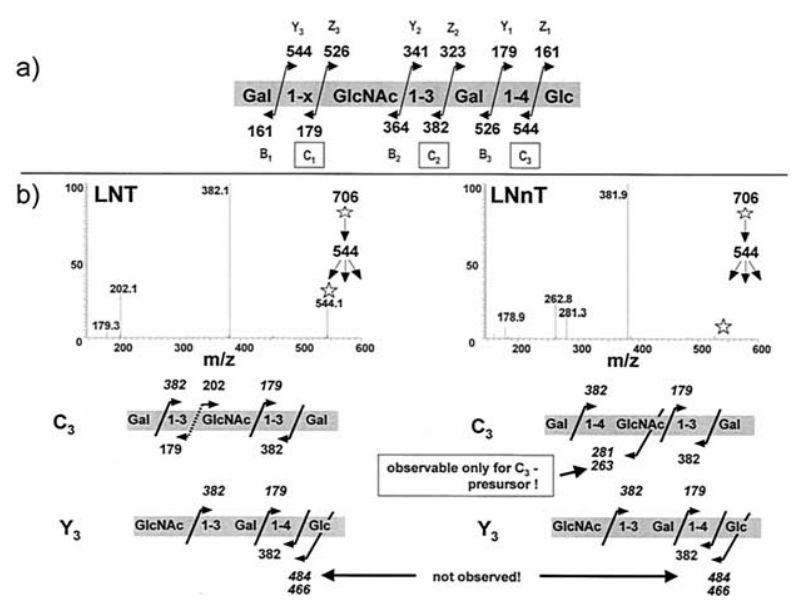

Figure 10. (a) illustrates the possible fragment ions masses of deprotonated LNT $(x=3)$ or LNnT $(x=4)$ corresponding to $\mathrm{B} / \mathrm{C} / \mathrm{Y} / \mathrm{Z}$-type fragmentations. The doubly framed masses are not observed in the $\mathrm{MS}^{2}$ spectra [see Figure 2(a) and (2b)]. (b) shows the MS ${ }^{3}$ spectra of the fragment ion with $\mathrm{m} / \mathrm{z} 544$ generated from LNT (left) and LNnT (right); the schemes below illustrate possible fragment ions of the $C$ - and $Y$-type of the $C_{3}$ and $Y_{3}$ ions generated from LNT and LNnT (for further discussion see text). 
cross-ring fragments between the incremental molecular masses according to the losses of intact monosaccharide subunits points to a $1 \rightarrow 3$-linkage which is present, for instance, between lactose and LacNAc or Lac-neoLAc subunits.

In general, branching points (see Table 1) are indicated by a loss of $[n(365)+$ a $(146)+18)]$, which also occur due to $\beta$-elimination (with " $\mathrm{n}$ " $N$-acetyllactosamines and " $\mathrm{a}$ " fucoses). This results in a big gap in the $\mathrm{MS}^{\mathrm{n}}$ spectrum, which is not observed in linear structures. This prevents further linkage analysis in this branch, but its composition ( $n$ and a) can be revealed. To obtain more structural information, combination of specific enzymatic cleavages of either the " $1 \rightarrow 6$ branch" $^{\prime}$ or the " $1 \rightarrow 3$ branch" needs to be tested. The branching point is confirmed by a further mass increment of 144 $\mathrm{Da}\left(\mathrm{Gal}-2 \mathrm{H}_{2} \mathrm{O}=144 \mathrm{Da}\right)$; this loss, accompanied by a cross-ring cleavage product (loss of $72 \mathrm{Da}$ ), is also characteristic for branching points.

This is consistent with the observations made with linear structures, that branched $1 \rightarrow 3$ linkages (e.g., fucoses) become relatively unstable, only if the deprotonated reducing end (including deprotonated C-fragment ions) is located at the monosaccharide subunit which contains the branching site. It is stressed here that no unselective losses of $1 \rightarrow 3$ linked residues occur. As discussed above, this makes the analysis of linkage and branching as well as the localization of fucose residues possible.

\section{Conclusion}

The capability of a quadrupole ion-trap mass spectrometer to carry out consecutive fragmentations of molecules can be applied to structural elucidation of complex oligosaccharides in the negative ion mode when using deprotonated molecules as precursor ions. By investigation of a series of isomeric glycoforms, fragmentation rules for the structural features of human milk oligosaccharides could be obtained. The fragmentation spectra of negative ions provide information about linkage types and branching positions and can be applied to differentiate between isomeric molecules. Even the position of fucose residues and their linkage type can be elucidated. The unambiguous interpretation of the mass spectra is based on characteristic mass increments which arise from consecutive C-type fragmentation.

This method has been applied to complex isomeric mixtures as demonstrated in Part II of this paper.

Future work should also be addressed to the question whether this useful method for human milk oligosaccharides, for which the building blocks have already been determined by other analytical methods, can also be applied for other classes of oligosaccharides, e.g., for such sugars derived from glycoproteins.

\section{Acknowledgments}

The authors thank Dr. Hildegard Geyer and Dr. U. Bahr for helpful discussions. They also gratefully acknowledge financial support by the Bundesministerium für Bildung und Forschung (BMBF) under grant BEO/22 0311229.

\section{References}

1. Dwek, R. A. Chem. Rev. 1996, 96, 683.

2. Dell, A. Methods Enzymol. 1990, 193, 647.

3. Egge, H.; Peter-Katalinic, J. Mass Spectrom. Rev. 1997, 6, 331.

4. Settineri, C. A.; Burlingame, A. L. Carbohydrate Analysis; Journal of Chromatography Library. Elsevier: Amsterdam, 1995; p 447.

5. Harvey, D. J. Mass Spectrom. Rev. 1999, 18, 349.

6. Domon, B.; Costello, C. E. Glycoconj. J. 1988, 5, 397.

7. Stahl, B.; Steup, M.; Karas, M.; Hillenkamp, F. Anal. Chem. 1991, 63, 1463.

8. Spengler, B. J. Mass Spectrom. 1997, 32, 1019.

9. Harvey, D. J.; Küster, B.; Naven, T. J. P. Glycoconj. J. 1998, 15, 333.

10. Spengler, B.; Kirsch, D.; Kaufmann, R.; Lemoine, J. J. Org. Mass Spectrom. 1994, 29, 782.

11. Lemoine, J.; Chirat, F.; Domon, B. J. Mass Spectrom. 1996, 31, 908.

12. Harvey, D. J.; Naven, T. J. P.; Küster, B.; Bateman, R. H.; Green, M.; Critchley, G. Rapid. Commun. Mass Spectrom. 1995, 9, 1556.

13. Okamoto, M.; Takahashi, K.; Doi, T.; Takimoto, Y. Anal. Chem. 1997, 69, 2919.

14. Talbo, G.; Mann, M. Rapid Commun. Mass Spectrom. 1996, 10, 100.

15. Viseux, N.; Costello, C. E.; Domon, B. J. Mass Spectrom. 1999, 34,364 .

16. Pfenninger, A.; Karas, M.; Finke, B.; Stahl, B.; Sawatzki, G. J. Mass Spectrom. 1999, 34, 99.

17. Naven, T. J. P.; Harvey, D. J.; Brown, J.; Critchley, G. Rapid Commun. Mass Spectrom. 1997, 11, 1681.

18. Spina, E.; Cozzolino, R.; Ryan, E.; Garozzo, D. J. Mass. Spectrom. 2000, 35, 1042.

19. Sutton, C. W.; O'Neill, J. A.; Cottrell, J. S. Anal. Biochem. 1994, $218,34$.

20. Küster, B.; Naven, T. J. P.; Harvey, D. J. J. Mass Spectrom. 1996, 31, 1131.

21. Yang, Y.; Orlando, R. Anal. Chem. 1996, 68, 570.

22. Mechref, Y.; Novotny, M. V. Anal. Chem. 1998, 70, 455.

23. Geyer, H.; Schmitt, S.; Wuhrer, M.; Geyer, R. Anal. Chem. 1999, $71,476$.

24. Cancilla, M. T.; Penn, S. G.; Lebrilla, C. B. Anal. Chem. 1998, 70, 663.

25. Wong, A. W.; Cancilla, M. T.; Voss, L. R.; Lebrilla, C. B. Anal. Chem. 1999, 71, 205.

26. Hayes, R. N.; Gross, M. L. Methods Enzymol. 1990, 193, 237.

27. Yost, R. A.; Boyd, R. K. Methods Enzymol. 1990, 193, 154.

28. Reinhold, V. N.; Reinhold, B. B.; Costello, C. E. Anal. Chem. 1995, 67, 1772.

29. Sheeley, D. M.; Reinhold, V. N. Anal. Chem. 1998, 70, 3053.

30. Reinhold, V. N.; Reinhold, B. B.; Chan, S. Methods Enzymol. 1996, $271,377$.

31. Souluki, T.; Reinhold, B. B.; Costello, C. E.; O'Malley, M.; Guan, S.; Marshall, A. G. Anal. Chem. 1998, 70, 857.

32. Fura, A.; Leary, J. A. Anal. Chem. 1993, 65, 2805.

33. Smith, G.; Leary, J. A. J. Am. Chem. Soc. 1996, 118, 3293.

34. Smith, G.; Leary, J. A. J. Am. Soc. Mass Spectrom. 1996, 7, 953.

35. König, S.; Leary, J. A. J. Am. Soc. Mass Spectrom. 1998, 9, 1125.

36. Viseux, N.; de Hoffmann, E.; Domon, B. Anal. Chem. 1998, 70, 4951.

37. Spengler, B.; Dolce, J. W.; Cotter, R. J. Anal. Chem. 1990, 62, 1731.

38. Hofmeister, G. E.; Zhou, Z.; Leary, J. A. J. Am. Chem. Soc. 1991, 113,5964 
39. Domon, B.; Müller, D. R.; Richter, W. J. Org. Mass Spectrom. 1989, 24, 357.

40. Smith, G.; Leary, J. A. J. Am. Soc. Mass Spectrom. 1996, 7, 953.

41. Bahr, U.; Pfenninger, A.; Karas, M.; Stahl, B. Anal. Chem. 1997, 69,4530 .

42. Asam, G. L.; Glish, G. J. Am. Soc. Mass Spectrom. 1997, 8, 987.

43. Mulroney, B.; Traeger, J. C.; Stone, B. A. J. Mass Spectrom. 1995, 30, 1277.

44. Garozzo, G.; Impallomeni, E.; Spina, E.; Green, B. N.; Hutton, T. Carbohydr. Res. 1991, 221, 1283.

45. Bahr, U.; Karas, M.; Schubert-Zsilavecz, M. Proceedings of the 46th ASMS Conference on Mass Spectrometry and Allied Topics; Orlando, FL, May, 1998; p 2.

46. Friedl, C. H.; Lochnit, G.; Geyer, R.; Karas, M.; Bahr, U. Anal. Biochem. 2000, 284, 279.

47. Kunz, C.; Rudolf, S. Acta Paediatr. 1993, 82, 903.

48. Kobata, A.; Yamashita, K.; Tachibana, Y. Methods Enzymol. 1978, 50, 216
49. Kuntz, R.; Dabrowski, U.; Dabrowski, J.; Ebersold, A.; PeterKatalinic, J.; Egge, H. Biol. Chem. Hoppe-Seyler 1988, 369, 257.

50. Strecker, G.; Wieruszeski, J. M.; Michalksi, J. C.; Montreuil, J. Glycoconj. J. 1989, 6, 169.

51. Stahl, B.; Thurl, S.; Zeng, J.; Karas, M.; Hillenkamp, F.; Steup, M.; Sawatzki, G. Anal. Biochem. 1994, 223, 218.

52. Finke, B.; Stahl, B.; Pfenninger, A.; Karas, M.; Daniel, H.; Sawatzki, G. Anal. Chem. 1999, 71, 3755.

53. Thurl, S.; Offermanns, J.; Müller-Werner, B.; Sawatzki, G. J. Chromatogr. 1991, 568, 291.

54. Thurl, S.; Müller-Werner, B.; Sawatzki, G. Anal. Biochem. 1996, 235, 202.

55. Chai, W.; Piskarev, V.; Lawson, A. M. Anal. Chem. 2001, 73, 651.

56. Bier, M. E.; Schwartz, J. C. In Electrospray Ionization Mass Spectrometry; Cole, R. B., Ed.; John Wiley and Sons: New York, 1997; p 235.

57. Kennedy, J. F. Carbohydrate Chemistry. Clarendon Press: Oxford, 1988, 269. 